\title{
Per Connection Classifier Load Balancing dan Failover MikroTik pada Dua Line Internet
}

\author{
Taufik Rahman ${ }^{1)}$, Eko Sulistianto ${ }^{2}$, Aji Sudibyo ${ }^{3)}$, Sumarna $^{4}$, Bambang Wijonarko ${ }^{5)}$ \\ 1,3,5 Teknologi Komputer, Fakultas Teknologi dan Informatika Universitas Bina Sarana Informatika \\ Jl. Kamal Raya No.18, RT.6/RW.3, Cengkareng Barat, Kecamatan Cengkareng, Kota Jakarta Barat, \\ Daerah Khusus Ibukota Jakarta 11730 \\ ${ }^{2,4}$ Program Studi Sistem Informasi, Universitas Nusa Mandiri \\ J1. Jatiwaringin No. 2, Cipinang Melayu, Jakarta Timur 13620 \\ Co Responden Email: taufik@bsi.ac.id
}

Article history

Received June 11, 2021

Revised June 14, 2021

Accepted June 27, 2021

Available online June 30, 2021

Keywords

PCC,

Load Balancing,

Failover,

MikroTik

Router.

Riwayat

Diterima 11 Juni 2021

Revisi 14 Juni 2021

Disetujui 27 Juni 2021

Terbit 30 Juni 2021

Kata Kunci

PCC,

Load Balancing,

Failover,

MikroTik,

Router.

\section{ABSTRACT}

The internet is a primary need for all people. Many companies integrate Web sites with back-office systems such as databases. The problem that occurs is that the utilization of the two internet lines is less than optimal and efficient. This happens because the two lines are not in the same network. Likewise at PT. ICC Export, it can be seen from the two internet lines that are not managed and go directly to the switch. so that there is often a buildup of internet traffic on one line, resulting in slow internet access. When one internet line is disconnected, the internet connection will automatically be disconnected because the modem is not managed by the router, so it can't back up automatically. The purpose of making load balancing and failover at PT. ICC Export to try a solution if one of the two internet lines is dead, is the other line active and if both lines are active then they can run together. The result is the implementation of load balancing using the PCC method on the GNS3 application successfully spreading the number of connection loads on all ISP gateways used in a balanced way, the fail over technique works well, when one of the gateways is disconnected or experiencing connection problems, all internet connection loads will be transferred automatically to another active gateway.

ABSTRAK
Internet menjadi kebutuhan primer semua kalangan. Banyak perusahaan
mengintegrasikan situs Web dengan sistem back-office seperti database.
Masalah yang terjadi adalah pemanfaatan ke dua line internet tersebut yang
kurang maksimal dan efisien. Hal ini terjadi karena ke dua line tersebut tidak
dalam satu jaringan. Demikian pula pada PT. ICC Export, terlihat dari dua line
internet yang tidak di manage dan langsung ke switch. sehingga sering terjadi
penumpukan trafik internet pada satu line, akibatnya akses internet lambat.
Ketika salah satu line internet terputus maka koneksi internet pun otomatis akan
terputus karena modem yang satu tidak di manage oleh router, sehingga tidak
bisa membackup secara otomatis. Maksud dibuatnya load balancing dan failover
pada PT. ICC Export untuk mencoba solusi jika satu dari dua line internet mati,
apakah line satunya aktif dan jika kedua line aktif maka dapat berjalan bersama.
Hasil nya implementasi load balancing menggunakan metode PCC pada aplikasi
GNS3 berhasil menyebarkan jumlah beban koneksi pada semua gateway ISP
yang digunakan secara seimbang, teknik fail over berfungsi dengan baik, ketika
salah satu gateway terputus atau mengalami gangguan koneksinya maka semua
beban koneksi internet akan dialihkan secara otomatis ke gateway lainnya yang
aktif.




\section{PENDAHULUAN}

Jaringan internet merupakan sarana prasarana untuk mendukung proses belajar dan bekerja. Beberapa masalah jaringan internet yang sering terjadi adalah koneksi internet terputus, koneksi lambat, dan output tidak sesuai dengan bandwidth yang dimiliki. Hal ini dapat diakomodasi dengan menggunakan 2 (dua) unit modem internet dari ISP yang berbeda yang dipadukan dengan proses load balancing. Load Balancing digunakan untuk menggabungkan dua modem internet sehingga satu koneksi dapat menjadi koneksi cadangan jika koneksi utama terputus.

Load balancing merupakan cara untuk menyebarkan tugas ke berbagai sumber daya. Dengan memproses tugas dan mengarahkan sesi di server yang berbeda, penyeimbangan beban membantu jaringan menghindari waktu henti yang mengganggu dan memberikan kinerja yang optimal kepada pengguna.(Mishra Assistant Professor, 2015).

Penerapan algoritma load balancing memungkinkan peningkatan perilaku jaringan yang ditentukan perangkat lunak dalam hal kualitas layanan, meningkatkan bandwidth, mengurangi waktu respons, dan mendistribusikan beban tautan secara optimal.(Duque, Beltrán, \& Leguizamón, 2018).

Proses Load Balancing pada Router MikroTik RB750 menggunakan metode Static Route with Address List, Equal-Cost MultiPath (ECMP), Peer Connection Classifier (PCC), dan Nth dapat mengatasi masalah tersebut. Jika koneksi utama terputus maka koneksi internet akan otomatis berpindah pada jalur koneksi yang masih aktif. Sehingga tidak mengganggu pengguna internet dalam kegiatan belajar dan bekerja dalam suatu organisasi.(Christanto, Susanto, \& Priyanto, 2019).

Per Connection Classifier adalah opsi mangle yang mengurutkan data ke dalam aliran yang dapat ditandai untuk identifikasi nanti. PCC membagi data yang masuk ke dalam aliran dan kemudian menggunakan aturan perutean untuk mengurutkan lalu lintas secara merata (atau tidak) di beberapa koneksi WAN. Fungsi PCC yang terdapat pada "Mangle Facility" untuk mengurutkan lalu lintas ke dalam aliran.(Discher, 2016).

Implementasi jaringan failover dapat menjaga keandalan sistem jaringan PT PLN
(Persero) UP3B Kaltim ketika terjadi fiber cut atau terputusanya jaringan backbone utama dan secara otomatis akan melakukan failover pada jalur backup, hal ini terbukti bahwa failover juga dapat diterapkan pada layer 2 (data link) sebagai alternatif penggunaan di layer 3 (network) pada umumnya. (Djumhadi \& Roring, 2020).

Penerapan sistem Load Balancing dapat mengatasi masalah ketika salah satu ISP mengalami pemutusan hubungan. Hal ini terlihat dari peralihan koneksi otomatis ke gateway ISP yang aktif, sehingga kinerja jaringan tetap berjalan normal. Pengujian throughput pada pagi, siang, dan sore hari menunjukkan perubahan nilai yang sangat baik setelah diterapkan load balancing. Pengujian delay dan Packet Loss juga menunjukkan perubahan nilai dari buruk menjadi sangat baik setelah penerapan sistem Load Balancing.(Safrianti, 2021).

Redundansi dengan failover dapat menjadi solusi saat terjadi downtime pada node-node dalam jaringan. Failover adalah proses pemindahan koneksi ke jalur alternatif yang disebabkan oleh gangguan atau kelainan sistem atau perangkat keras atau jaringan.(Adhiwibowo \& Irawan, 2019).

Pengujian vailability server pada penelitian ini menggunakan teknologi failover cluster, setelah pengujian dilakukan maka didapatkan hasil, apabila terjadi kegagalan atau error pada server utama maka secara otomatis role server utama akan digantikan oleh server backup dengan resource yang sama dengan server utama. Adapun waktu perpindahan otomatis server, ketika server aktif mengalami kegagalan, maka hanya membutuhkan waktu kurang dari 5 detik.(Abdullah, Qidri, Nuryadi, \& Widianto, 2020).

Untuk menjamin kehandalan sistem, arsitektur yang diusulkan didukung dengan komponen load balancing, mekanisme failover dan replikasi database. Sistem telah diuji berasarkan kebutuhan fungsional dan kebutuhan non-fungsional yang sudah didefinisikan sesuai kebutuhan organisasi.(Setiawan et al., 2021).

Metode dan sistem untuk load balancing dan failover di antara perangkat gateway diungkapkan. Salah satu metode menyediakan untuk menetapkan penanganan transaksi komunikasi ke gateway. Metode tersebut mencakup menerima permintaan untuk lisensi 
dari perangkat komputasi pada gerbang kontrol dalam sekelompok perangkat gerbang termasuk sejumlah perangkat gerbang yang dikonfigurasi untuk mendukung komunikasi data yang dipisah secara kriptografis. Metode ini juga mencakup menetapkan komunikasi dari perangkat komputasi ke salah satu dari sejumlah perangkat gerbang berdasarkan algoritma penyeimbang beban, dan mengarahkan permintaan komunikasi ke perangkat gerbang yang ditetapkan.(Johnson, Wild, \& Quammen, 2012).

Internet sudah menjadi kebutuhan primer bagi semua kalangan, tidak terkecuali bagi kalangan pebisnis. Banyak perusahaan, terutama yang menerapkan perdagangan online, telah mengintegrasikan situs Web mereka dengan sistem back-office seperti database. Berbagai fasilitas yang ada di internet telah banyak membuktikan mampu mempercepat komunikasi dengan orang yang dituju. Email adalah salah satu contoh yang telah banyak dimanfaatkan oleh banyak orang untuk mengirim menerima dokumen. Chatting atau video conferencing juga mempercepat komunikasi yang dilakukan menggunakan koneksi internet.

Begitu juga pada PT. ICC Export, perusahaan berbasis diindonesia yang berdiri sejak tahun 1992 dalam bisnis kilang minyak kelapa sawit dan palm kernel oil. PT. ICC Export memiliki cakupan yang cukup luas telah merambah tujuh puluh lima persen dunia, Tidak hanya di timur tengah tapi juga di empat benua yaitu benua, Afrika, Asia, Australia, dan Eropa. Dengan kondisi tersebut PT. ICC Export sangat mengandalkan internet stabil, jika internet down dibutuhkan internet backup, minimal terdapat dua line internet yang di load balancing dan failover. untuk operasional perusahaan sehari - hari, seperti untuk kirim dan terima email, file sharing, chatting dan juga video conferencing.

Permasalahan jaringan pada PT. ICC Export, kurang efisien dalam pemanfaatan internet, terlihat dari dua line internet yang tidak di manage dan langsung ke switch. sehingga dengan keadaan skema jaringan yang sering terjadi penumpukan trafik internet pada satu line saja sehingga akses internet menjadi lambat. Ketika salah satu line internet terputus maka koneksi internet pun otomatis akan terputus karena modem yang satu tidak di manage oleh router MikroTik(Pauzhi \& Coronel, 2015), sehingga tidak bisa membackup secara otomatis. Maksud dari dibuatnya load balancing dan failover pada PT. ICC Export adalah untuk menjadi solusi jika salah dari dua line internet mati, jika kedua line aktif maka dapat berjalan berbarengan.

\section{METODE PENELITIAN}

Pada penelitian ini menggunakan model perancangan jaringan PPDIOO dengan 6 fase: Prepare (persiapan), Plan (Perencanaan), Design (Desain), Implement (Implementasi), Operate dan Optimize (Optimasi).(Jose, 2006)

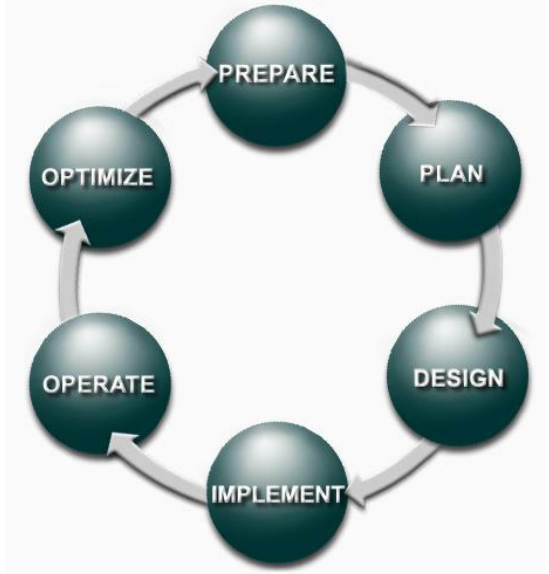

Gambar 1. Model PPDIOO

Metode perancangan jaringan PPDIOO mempunyai fase sebagai berikut:

\section{a. Fase Prepare}

Menetapkan kebutuhan apa saja yang dibutuhkan oleh PT.ICC Export dalam mengembangkan jaringan, dan mengusulkan konsep arsitektur yang dibutuhkan yang disesuaikan dengan kemampuan finansial pada perusahaan tersebut.

b. Fase Plan

Merancang konsep kebutuhan jaringan berdasarkan kepentingan dan kebutuhan pengguna. Fase ini mendeskripsikan karakteristik kebutuhan jaringan, yang memiliki tujuan untuk menilai gap analisis pada perancangan pada sebuah arsitektur.

\section{c. Fase Design}

Desain jaringan dikembangkan berdasarkan persyaratan teknis, dan persiapan yang diperoleh dari kondisi sebelumnya. Hasil desain termasuk didalamnya flow jaringan, dan daftar peralatan jaringan.

d. Implement (Implementasi)

Perangkat-perangkat akan disesuaikan dengan yang ada di PT. ICC Export. Setiap langkah dalam implementasi, akan menyertakan deskripsi, perkiraan waktu untuk 
penerapan, evaluasi, dan informasi lainnya sebagai referensi tambahan. Setelah di lakukan implementasi, dalam fase ini juga dilakukan pengujian untuk memastikan bahwa sistem telah berjalan.

\section{e. Operate (Operasi)}

Memastikan jaringan baru yang sudah terimplementasi di PT. ICC Export telah beroperasi dengan normal. Pengelolaan jaringan, pemeliharaan routing, dan mengelola kinerja. Tahapan ini akan dipantau untuk stabilitas dan kinerja jaringan, koreksi konfigurasi, dan kegiatan pemantauan kinerja,

f. Optimize (Optimasi)

Fase optimasi, memungkinkan untuk memodifikasi desain jaringan, jika terlalu banyak masalah jaringan yang ditimbulkan, dan untuk memperbaiki masalah kinerja.

Setelah sistem load balancing ini selesai kemudian akan di implementasikan pada jaringan komputer di PT. ICC Export, Bertujuan untuk menghindari overload kapasitas pemakaian bandwidth.

Analisa topologi jaringan PT. ICC Export yang sedang berjalan, tidak termasuk konfigurasi server dan firewall policy. Implementasi Load Balancing dan Failover menggunakan mikrotik routerboard RB750. Jalur internet yang digunakan dalam implementasi adalah dua line koneksi internet dengan dua Internet Service Provider (ISP) yang sama dan modem terpisah. Simulator aplikasi Graphical Network Simulator 3 (GNS3)(Rahman, 2017). Perancangan topologi jaringan menggunakan Microsoft Office Visio 2007.

\section{HASIL DAN PEMBAHASAN}

Selanjutnya hasil dari analisa pada PT. ICC Export, menggunakan topologi star. Topologi star adalah topologi jaringan komputer yang menggunakan concentrator (hub atau switch) sebagai media penghubung. Arsitektur jaringan nya hybrid, gabungan dari sifat pada jaringan client/server dan peer to peer. PT. ICC Export menggunakan dua line internet dari First Media dengan paket internet masing-masing modem 50 Mbps untuk kebutuhan usahanya. Dimana line internet First Media1 digunakan untuk lantai 1 dan lantai 2 sedangkan line internet First Media2 digunakan untuk lantai3, lantai 4, lantai 5 dan gudang logistik. Sebagai media penghubung antar node skema jaringan PT. ICC Export menggunakan concentrator (Hub atau Switch).

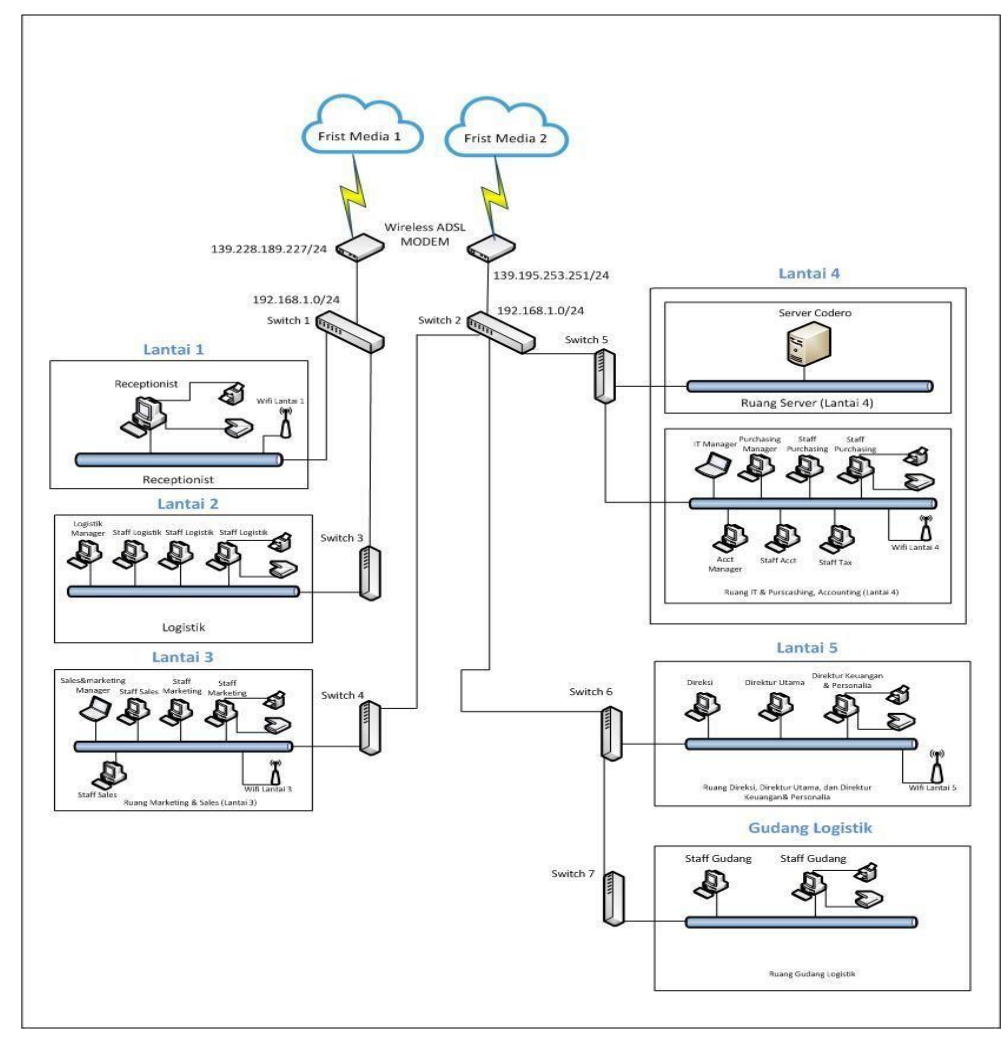

Sumber : PT. ICC Export

Gambar 2. Skema Jaringan PT. ICC Export 
Skema jaringan pada kantor pusat PT. ICC Export masih ada beberapa kekurangan sehingga diusulkan skema jaringan yang baru. Untuk meningkatkan keamanan jaringan, memisahkan ip address server dan client. Ip address server adalah 192.168.3.0/24 sedangkan untuk client menggunakan ip address 192.168.2.0/24. Sedangkan untuk mengatasi lambatnya koneksi internet juga tidak adanya jaringan backup, perlu menggabungkan dua line internet kedalam satu jaringan menggunakan router MikroTik dengan metode load balancing dan failover.

\section{Pembahasan}

Jaringan yang diusulkan pada PT. ICC Export, menggabungkan kedua line internet tersebut kedalam RouterBoard MikroTik dengan metode Peer Connection Classifier Load Balancing dan Failover.

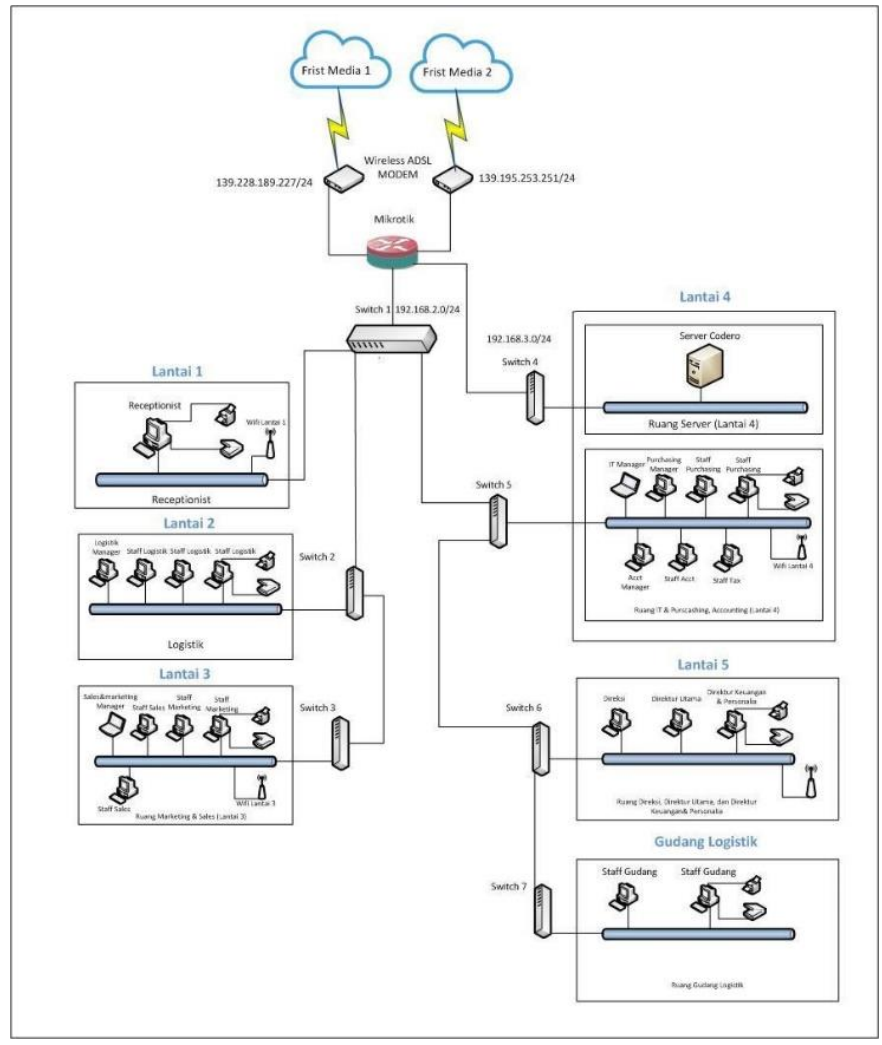

Sumber: Penelitian Pribadi

Gambar 3. Skema Jaringan Usulan

Berikut adalah tahapan dalam implementasi Per Connection Classifier Load Balance dan Failover yang disimulasikan dengan software GNS3:

1. Konfigurasi dasar MikroTik
Dalam tahapan ini berisi konfigurasi interface di MikroTik yang akan digunakan dalam implementasi tersebut. Selain itu di tahap ini ini juga dilakukan konfigurasi IP Address pada masing-masing interface dan konfigurasi DNS server.

Tabel 1. IP Address

\begin{tabular}{lll}
\hline Interface & Nama & IP Address \\
\hline Ether0 & Ether1-firstmedia1 & $139.228 .189 .1 / 24$ \\
Ether1 & Ether2-Firstmedia2 & $139.195 .253 .1 / 24$ \\
Ether2 & Ether3-lan & $192.168 .2 .1 / 24$ \\
Ether3 & Ether4-server & $192.168 .3 .1 / 24$ \\
\hline
\end{tabular}

Terdapat interface yang ada di sisi MikroTik dengan penjelasan sebagai berikut : a. Ether1-fristmedial merupakan interface yang terhubung dengan Modem ADSL ISP. 
b. Ether2-firstmedia2 merupakan interface yang terhubung dengan Modem ADSL ISP.

c. Ether3-server merupakan interface yang terhubung dengan jaringan Server.

d. Ether4-lan merupakan interface yang terhubung dengan jaringan client.

2. Konfigurasi NAT

Setelah konfigurasi dasar MikroTik selesai, selanjutnya menambahkan konfigurasi NAT (Network Address Translation). NAT berguna agar komputer server dan client dapat menggunakan internet.

3. Konfigurasi Mangle

Mangle digunakan untuk melakukan penandaan pada suatu paket, penandaan yang dilakukan sesuai dengan kondisi dan syarat yang kita inginkan. Proses penandaan ini berdasarkan pada hasil satatefull packet inspection, yaitu: scr-IP, dst-IP, scr-port dan dst-port. Pada proses mangle terdapat metode PCC dimana penandaan connection dilakukan dengan menggunakan metode hashing(Cristescu, Croitoru, \& Sorici, 2016).

4. Pengaturan Routing

Berdasarkan routing mark yang sudah dibuat pada konfigurasi mangle, routing-mark pertama menggunakan ISP1 (Frist Media1) dan routing-mark yang kedua akan menggunakan gateway ISP2 (Frist Media2).

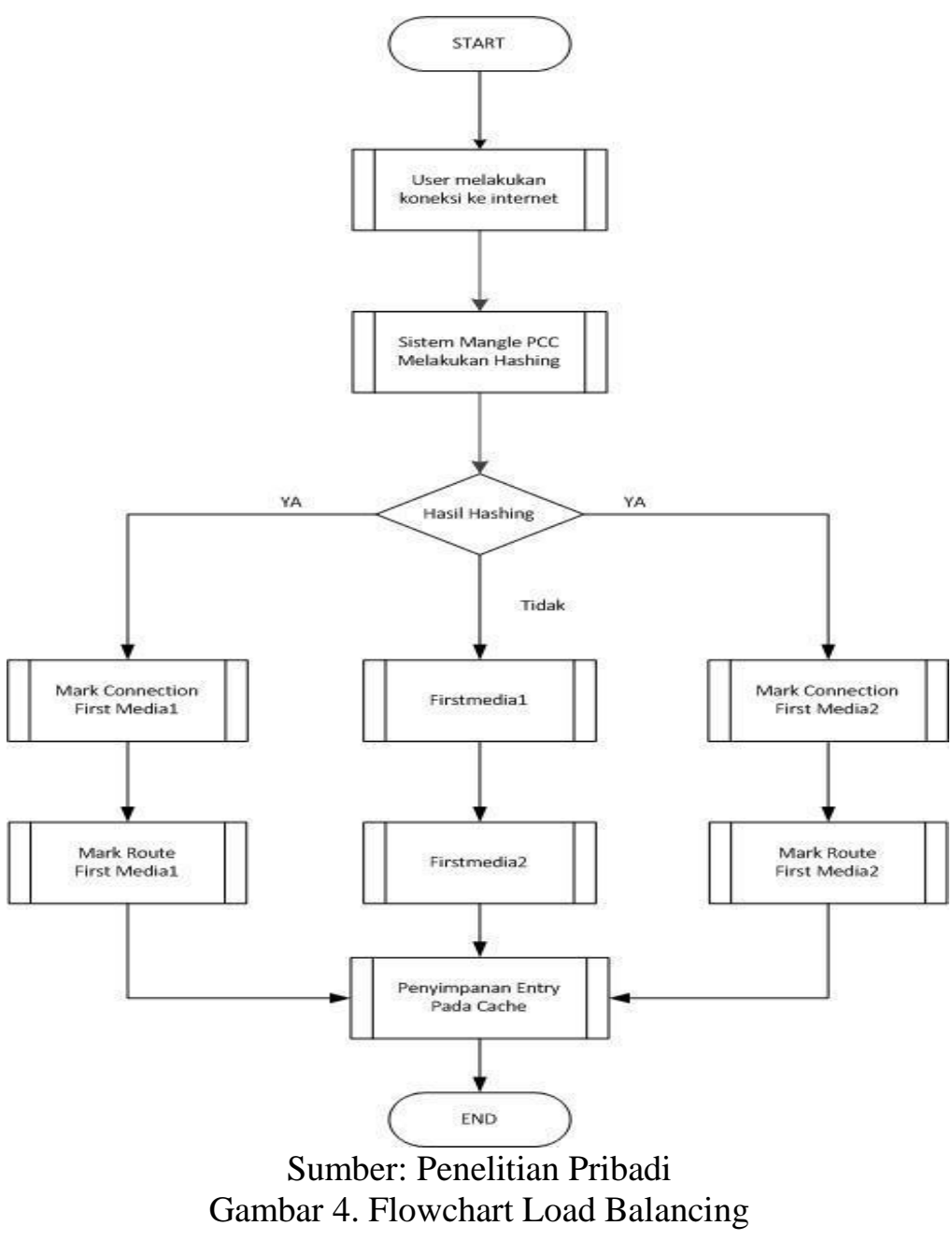

\section{Perancangan Failover}

Metode yang digunakan adalah memanfaatkan proses pemeriksaan dengan mengirimkan ICMP (Internet Control Message Protocol)(Yuan, Du, Yue, \& Ma, 2020) echo request kepada sebuah alamat yang dapat digunakan untuk mendeteksi kegagalan jalur. Dengan cara ini maka kegagalan jalur yang disebabkan oleh gagalnya sebuah hop dalam proses transaksi data juga dapat terdeteksi. Dibawah ini merupakan tabel rule yang akan di buat jika terjadi putusnya satu line internet. 
Tabel 2. Rule pada saat putusnya koneksi internet

\begin{tabular}{lll}
\hline First & First & Rule \\
\hline Hidup & Hidup & Menggunakan gateway semua ISP \\
Mati & Hidup & Menggunakan Gateway Frist Media2 \\
Hidup & Mati & Menggunakan gateway Frist Media1 \\
Mati & Mati & - \\
\hline
\end{tabular}

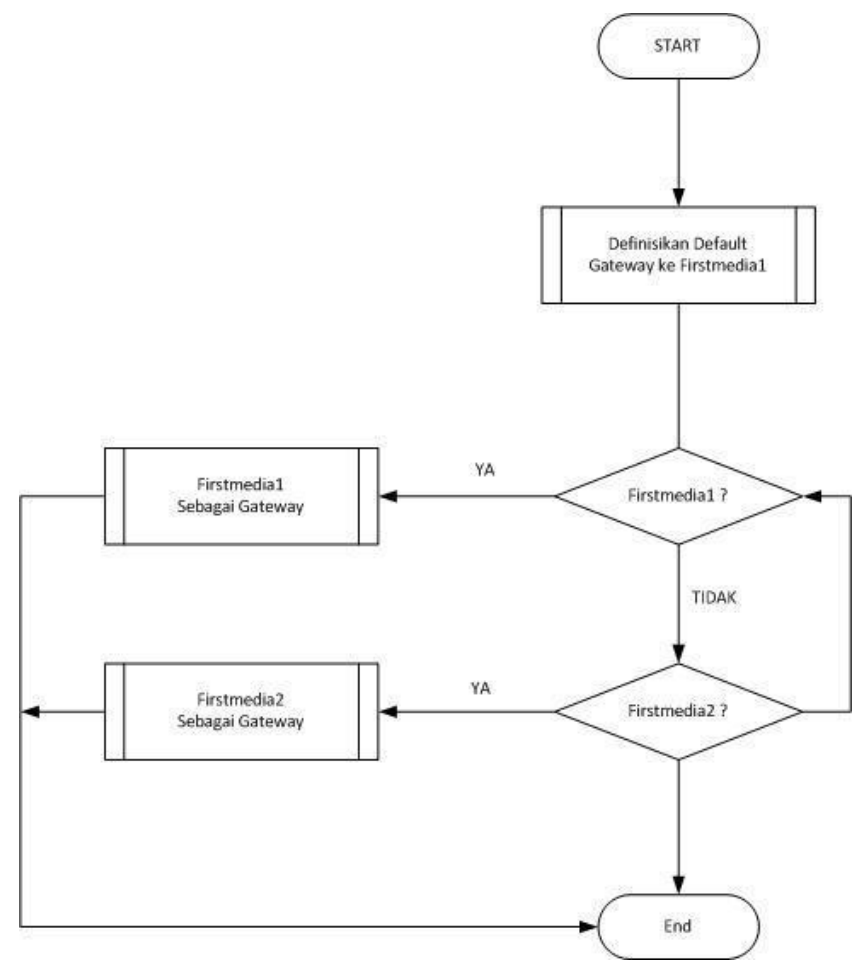

Sumber: Penelitian Pribadi

Gambar 5. Flowchart Failover

Selanjutnya konfigurasi pada raouterboard MikroTik.

1. Inisialisai Interface MikroTik

Inisialisai interface berguna untuk memudahkan konfigurasi MikroTik dengan cara memberikan nama pada masing-masing interface sesuai dengan fungsi dan keinginan. Perintah- perintah yang dilakukan adalah sebagai berikut

[admin@MikroTik] > interface set 0 name=ether1-firstmedial [admin@MikroTik] > interface set 1 name=ether2-firstmedia 2 [admin@MikroTik] > interface set 2 name=ether3-lan [admin@MikroTik]> interface set 3 name=ether4-server

Perintah "set0" merupakan perintah untuk mengkonfigurasi interface ether1 yang terdapat pada MikroTik dengan perintah menghidupkan interface dan memberi nama interface yaitu ether1-firstmedia1. Begitu pula untuk perintah-perintah lainnya.

2. Pemberian alamat ip address
Pada tahap ini akan dilakukan pemberian IP address pada tiap interface yang digunakan untuk implementasi load balancing dan failover. Untuk melakukan pemeberian IP address pada MikroTik menggunakan perintah sebagai berikut:

[admin@MikroTik] > ip address add address $=139.228 .189 .1 / 24$ interface $=$ ether 1 firstmedial

[admin@MikroTik] > ip address add address=139.195.253.1/24 interface $=$ ether2firstmedia2

[admin@MikroTik]>ip address add address $=192.168 .2 .1 / 24$ interface $=$ ether 3 -lan

[admin@MikroTik] > ip address add address $=192.168 .3 .1 / 24 \quad$ interface $=$ ether 4 server

Baris pertama memerintahkan untuk memberikan interface Ether1- firstmedial dengan IP address 139.194.138.1 dengan subnetting /24 yaitu : 255.255.255.0, keterangan selanjutnya seperti gambar 6 . 


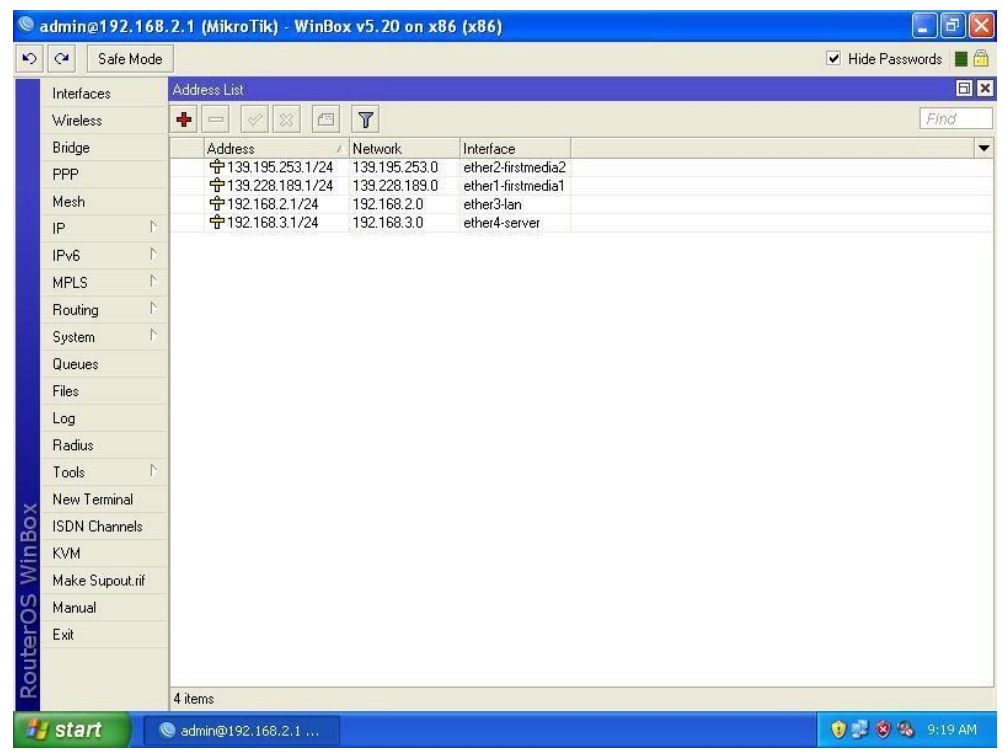

Sumber: Penelitian Pribadi

Gambar 6. IP address pada masing-masing interface

3. Konfigurasi IP DNS Server

DNS server berguna untuk memetakan host name sebuah komputer ke IP Address. Pada tahap ini alamat DNS yang digunakan merupakan IP dari masing - masing modem ISP. Konfigurasi sebagai berikut:

[admin@MikroTik] > ip dns set server $=139.228 .189 .227$ allow- remoterequest=yes

[admin@MikroTik] > ip dns set server $=139.195 .253 .251$ allow-remoterequest $=$ yes

4. Konfigurasi NAT ( Network Address Translation)

Agar komputer client dapat terhubung dengsn internet, maka perlu dilakukan translasi dari ip private ke ip public. Berikut ini adalah konfigurasi perintahnya:

[admin@MikroTik] > ip firewall nat add chain=srcnat out - interface $=$ ether 1 firstmedial action=masquerade

[admin@MikroTik] > ip firewall nat add chain=srcnat out $\quad$ interface $=$ ether 2 firstmedia 2 action=masquerade

5. Konfigurasi Mangle

tahapan untuk melakukan konfigurasi mangle pada MikroTik:

a. Dimulai dengan melakukan penandaan koneksi yang berasal dari luar jaringan interface public yang menuju alamat lokal. Penandaan dilakukan dengan mengatur koneksi yang berasal dari ISP 1 akan di beri tanda "conn-firstmedial" dan koneksi yang berasal dari ISP 2 akan diberi tanda "connfirstmedia2" konfigurasinya sebagai berikut:
[admin@MikroTik] > ip firewall mangle add chain=input in- interface =etherlfirstmedial action=mark-connection newconnection mark=conn-firstmedial passthrough=yes

[admin@MikroTik] > ip firewall mangle add chain=input in- interface $=$ ether 2 firstmedia2 action=mark-connection newconnection mark=conn-firstmedia2 passthrough=yes

b. Tahap selanjutnya melakukan penandaan routing mark sebagai jalur paket connection yang sudah ditandai yang akan keluar dari router. Untuk tiap-tiap koneksi dengan "conn-firstmedial" akan diberi markrouting "to-firstmedial" yang akan di lewatkan pada interface ether1-firstmedia1 sedangkan koneksi yang di tandai "connfirstmedia2" akan diberikan mark-routing "tofirstmedia2". Konfigurasinya adalah sebagai berikut:

[admin@MikroTik] > ip firewall mangle add chain=output connection-mark=ether 1 firstmedial action=mark-routing new-routing mark=to-firstmedial passthrough=yes

[admin@MikroTik] > ip firewall mangle add chain=output connection-mark=ether2firstmedia 2 action=mark-routing new-routing mark=to-firstmedia 2 passthrough=yes

c. Setelah dilakukan penandaan koneksi, maka langkah selanjutnya adalah melakukan pembagian jalur koneksi menjadi dua jalur dengan dibantu algoritma PCC. Algoritma PCC menjumlahkan both address dan port 
pada masing-masing koneksi, kemudian dibagi oleh suatu bilangan.

Pada penelitian ini menggunakan dua sesuai dengan jumlah ISP yang digunakan. Kemudian sisa hasil baginya akan digunakan sebagai penanda jika sisa hasil bagi nol maka koneksi tersebut akan di tandai sebagai "connfirstmedia1" kemudian dilewatkan ke routing mark "to-firstmedial" yaitu menggunakan gateway ISP Firstmedia1. Dan jika hasil bagi satu maka koneksi tersebut akan ditandai sebagai "conn-firstmedia2" kemudian dilewatkan ke routing-mark "to-firstmedia2" yaitu ISP Firstmedia2. Konfigurasi dalam MikroTik sebagai berikut: [admin@MikroTik] $>$ ip firewall mangle add chain=prerouting ininterface=etherl-firstmedial dst-addresstype $=$ !local perconnectionclassifier $=$ both-address-andport $2 / 0 \quad$ action=mark - connection new-connection-mark=conn-firstmedial passtrough $=$ yes

[admin@MikroTik] > ip firewall mangle add chain=prerouting in - interface $=$ ether 2 firstmedia 2 dst-address-type=!local perconnection-classifier $=$ both- address-andport:2/1 action=mark- connection newconnection-mark $=$ conn-firstmedia 2 passtrough=yes

\section{d. Konfigurasi Routing}

konfigurasi routing tabel agar paket bisa diteruskan ke gateway ISP yang sesuai dengan marking- routing yang telah dibuat pada konfigurasi mangle dengan aturan mark-route "to-firstmedial" akan menggunakan gateway IP yang dimiliki ISP Firstmedia1. Konfigurasinya adalah sebagai berikut:

[admin@MikroTik] > ip route add address gateway $=139.228 .189 .227$ routing-mark $=$ to firstmedial check- gateway $=$ ping distance $=1$

[admin@MikroTik]> ip route add address dst-address $=0.0 \cdot 0.0 / 0$ gateway $=139.195 .253 .251$ routing - mark $=$ to firstmedia check- gateway $=$ ping distance $=1$

e. Konfigurasi Failover

Konfigurasi yang dibuat sebagai berikut:

[admin@MikroTik] > ip route add address dst-address $=0.0 .0 .0 / 0$ gateway=139.228.189.227 checkgateway =ping distance $=1$ [admin@MikroTik] > ip route add address dst-address $=0.0 .0 .0 / 0$

gateway $=139.195 .253 .251$

checkgateway $=$ ping distance $=2$

\section{Pengujian Jaringan}

Pada pengujian jaringan sebelum dan sesudah load balancing dan failover berhasil di implementasikan. Pengujian dilakukan untuk mengetahui sejauh mana sistem yang telah dibangun berhasil dengan baik dalam mengoptimalkan kinerja dari jaringan tersebut. Dalam pengujian jaringan menggunakan beberapa tools yang terdapat di winbox dan juga aplikasi berbasis web yaitu www.speedtest.net.

\section{Pengujian Jaringan Awal}

Pada tahap pengujian jaringan awal, menggunakan aplikasi berbasis web yaitu www.speedtest.net. Dalam pengujian jaringan tersebut akan di ketahui besarnya nilai download speed dan upload speed serta besarnya nilai ping dari ISP yang digunakan. Pengujian dengan melakukan lima kali pengujian pada server yang sama yaitu server yang berada di kuta dengan jarak sejauh 600mil dari tempat pengujian. Hasil pengujian seperti gambar 7 .

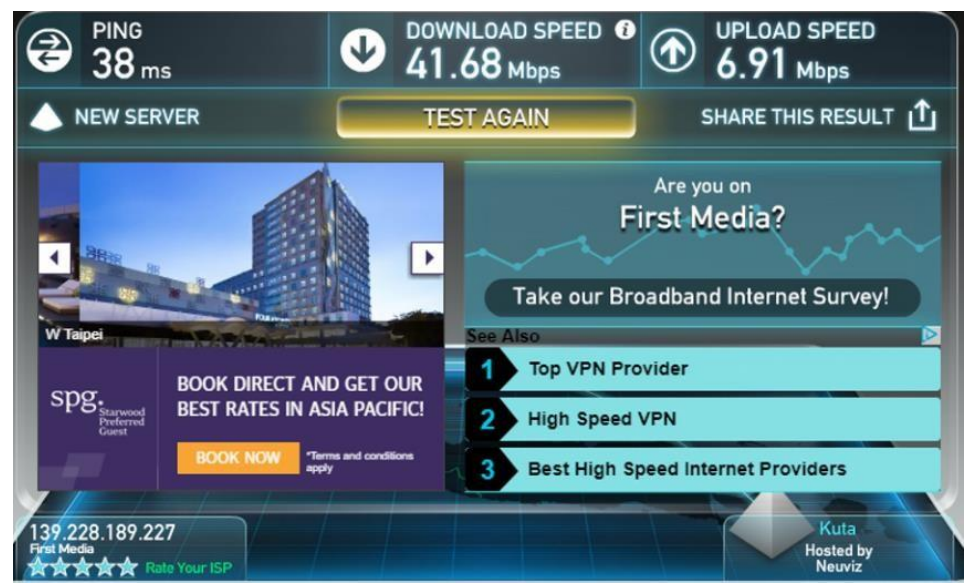

Sumber: Penelitian Pribadi

Gambar 7. Hasil Speedtest pengujian jaringan awal 
Data-data hasil speedtest tersebut dibuatkan tabel perbandingan.

Tabel 3. Pengujian speedtest jaringan awal

\begin{tabular}{llll}
\hline $\mathrm{N}$ & Ping (ms) & Download (Mbps) & Upload (Mbps) \\
\hline 1 & 38 & 36.85 & 7.24 \\
2 & 39 & 35.30 & 6.97 \\
3 & 38 & 34.16 & 6.77 \\
4 & 34 & 37.29 & 6.75 \\
5 & 38 & 41.68 & 6.91 \\
\hline
\end{tabular}

Ping digunakan untuk mengukur seberapa jauh jarak antara client dan server. Apabila nilai ping yang di hasilkan semakin besar makan akan semakin jelek kualitas koneksi tersebut sehingga mempengaruhi nilai mutu yang akan dihasilkan.

\section{Pengujian Jaringan Akhir}

Dalam tahapan ini menggunakan tools GNS3 dan Winbox untuk membuktikan simulasi loadbalancing dan failover berjalan dengan melakukan file sharing dan test ping, untuk hasil speedtest tidak bisa di terapkan karena rancangan aplikasi ini hanya sebatas simulasi dan belum di terapkan pada PT. ICC Export. Pengujian ini membagi dalam 2 fase yaitu :

1. Pengujian Efektifitas Penyetaraan Beban Pada Gateway ISP

Pada tahap ini, menggunakan tools yang ada pada winbox untuk melakukan pengujian. Hasil pengujian daat dilihat pada menu interface yang ada pada winbox. Berikut hasil pengujiannya:

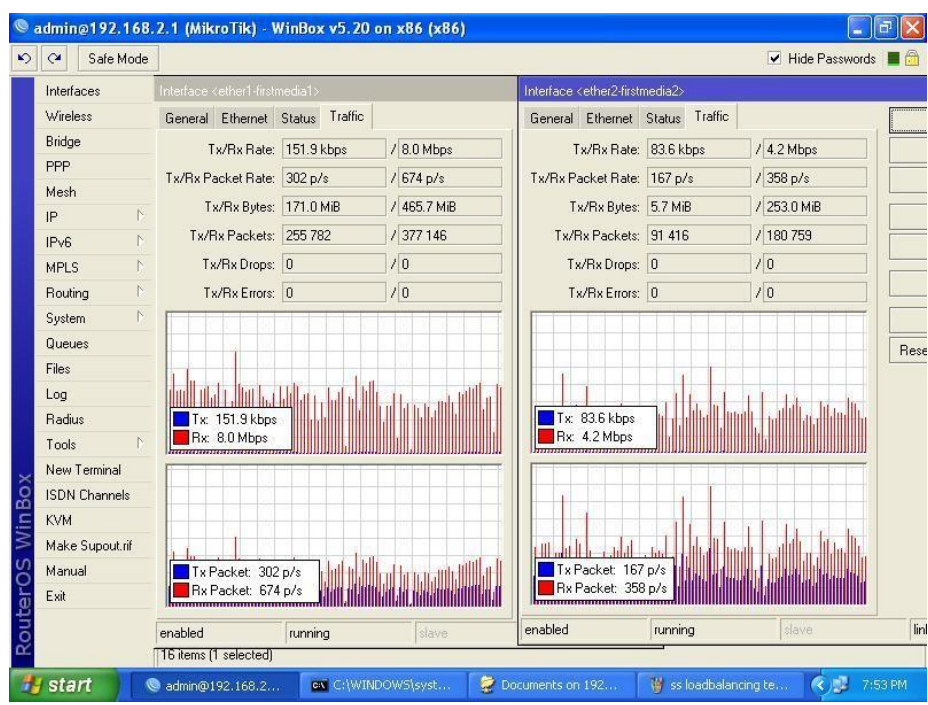

Sumber: Penelitian Pribadi

Gambar 8. Grafik koneksi pada gateway ISP

Parameter yang dilihat dari kedua traffic di interface tersebut adalah besarnya rata-rata penyebaran dari tiap-tiap gateway ISP. Pada interface tersebut terlihat besar packet dan bytes yang telah dilewati, hasil dari pengujian dimasukan kedalam tabel untuk memperjelas perbandingan dari masing-masing interface.

Tabel 4 Penyebaran paket data Load Balancing

\begin{tabular}{lllll}
\hline Gateway & \multicolumn{2}{l}{ Jumlah paket (Packet) } & \multicolumn{2}{c}{ Ukuran Paket $(\mathrm{kb})$} \\
\hline & $\mathrm{Tx}$ & $\mathrm{Rx}$ & $\mathrm{Tx}$ & $\mathrm{Rx}$ \\
Firtsmedia1 & 25578 & 377146 & 151,9 & 8,0 \\
Firtsmedia2 & 91416 & 180759 & 83,6 & 4,2 \\
\hline
\end{tabular}


Berdasarkan gambar 7 dan tabel 4 terlihat bahwa load balancing telah berhasil menyebarkan paket dan byte kesemua ISP. Besar paket antara Firstmedial dan Firstmedia2 ternyata tidak seimbang, ini di karenakan load balancing dan failover metode per connection classifier (PCC) hanya membagi beban berdasarkan koneksi yang terjadi bukan dari besar paket. Walaupaun demikian dari analisa di atas, dapat disimpulkan bahwa load balancing sudah berjalan cukup baik.

2. Pengujian Failover

Pada tahap ini menggunakan tools yang ada pada winbox untuk melakukan pengujian.
Pengujian untuk membuktikan apakah konfigurasi failover sudah bekerja dengan benar arau belum. Pengujian dilakukan dengan cara MikroTik melakukan traceroute ke suatu IP (Internet Protocol) yang telah ditentukan yaitu 192.168.1.2 (IP host2). Traceroute digunakan untuk mengetahui rute yang dilalui sebuah paket untuk mencapai tujuan. Interface router tersebut biasanya ditunjukan dengan sebuah alamat IP. Dari alamat IP tersebut kita bisa mengetahui alamat IP gateway yang sedang digunakan untuk koneksi internet. Berikut hasil pengujian tersebut:

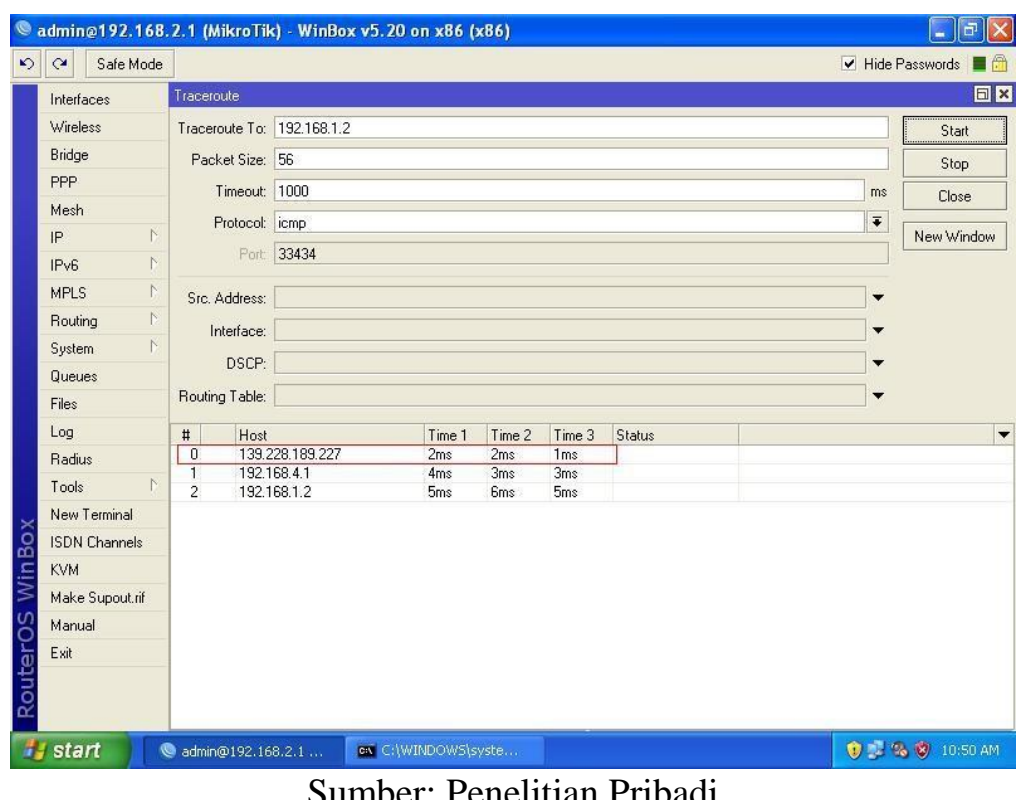

Gambar 9. Hasil traceroute ke IP 192.168.1.2 (Host2)

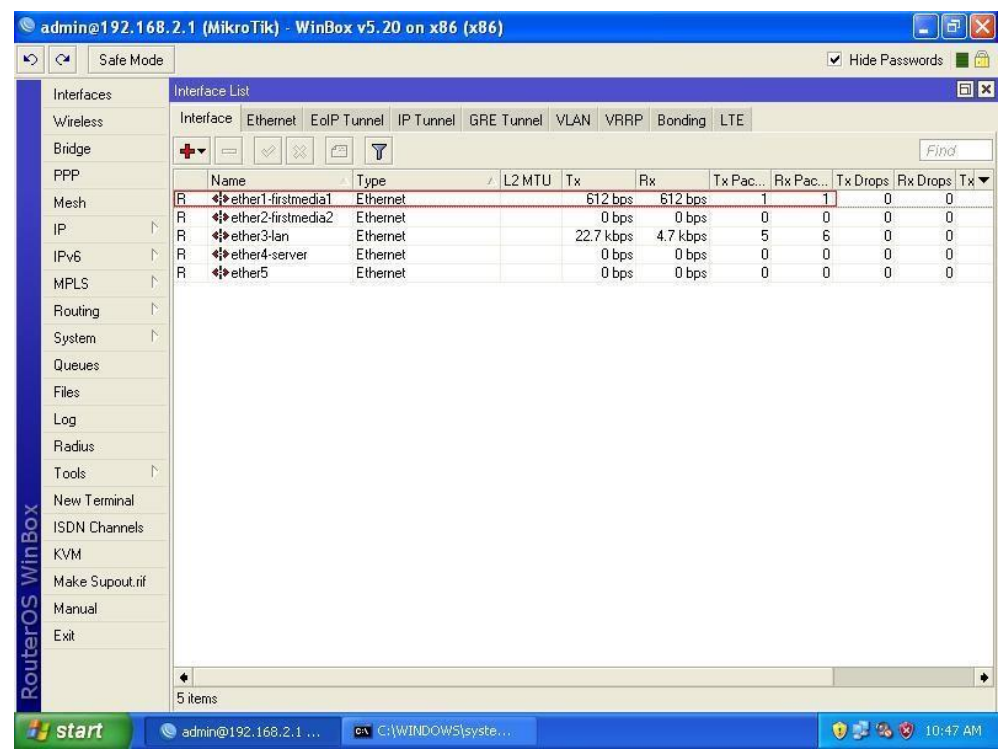

Sumber: Penelitian Pribadi

Gambar 10. Ether1-firstmedia1 sebagai gateway 
Dari gambar 9 menunjukan bahwa IP gateway yang sedang digunakan untuk koneksi adalah 139.228.189.227. Sedangkan gambar 10 , interface yang digunakan untuk koneksi internet adalah interface "Ether1-firstmedial", hal ini dilihat dari adanya lalu lintas data pada interface tersebut. Informasi IP gateway yang sedang digunakan sangat penting karena dengan adanya IP tersebut kita bisa mengetahui apabila ada perpindahan koneksi internet dari satu ISP ke ISP yang lain.

Setelah mengetahui gateway yang digunakan untuk melakukan koneksi, selanjutnya melakukan pemutusan salah satu line koneksi internet dengan cara mendisable salah satu interface di MikroTik.

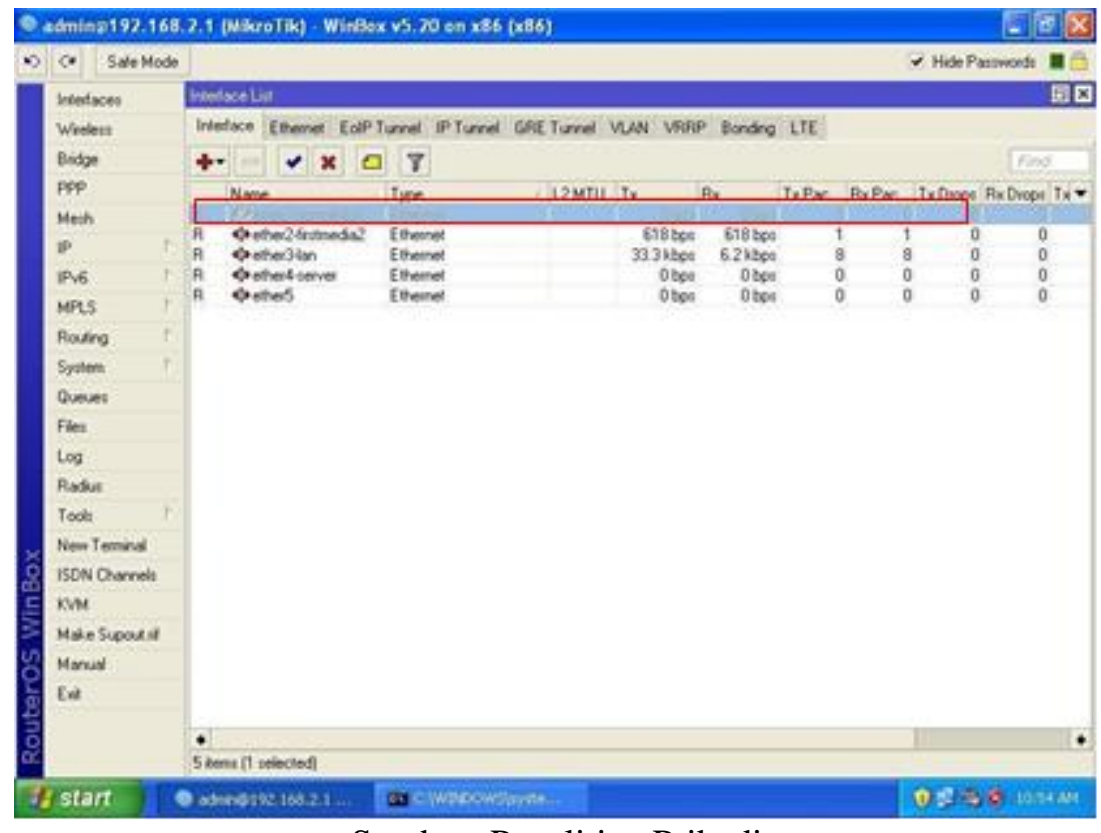

Sumber: Penelitian Pribadi

Gambar 11. Pemutusan koneksi internet pada interface "ether1-firstmedia1"

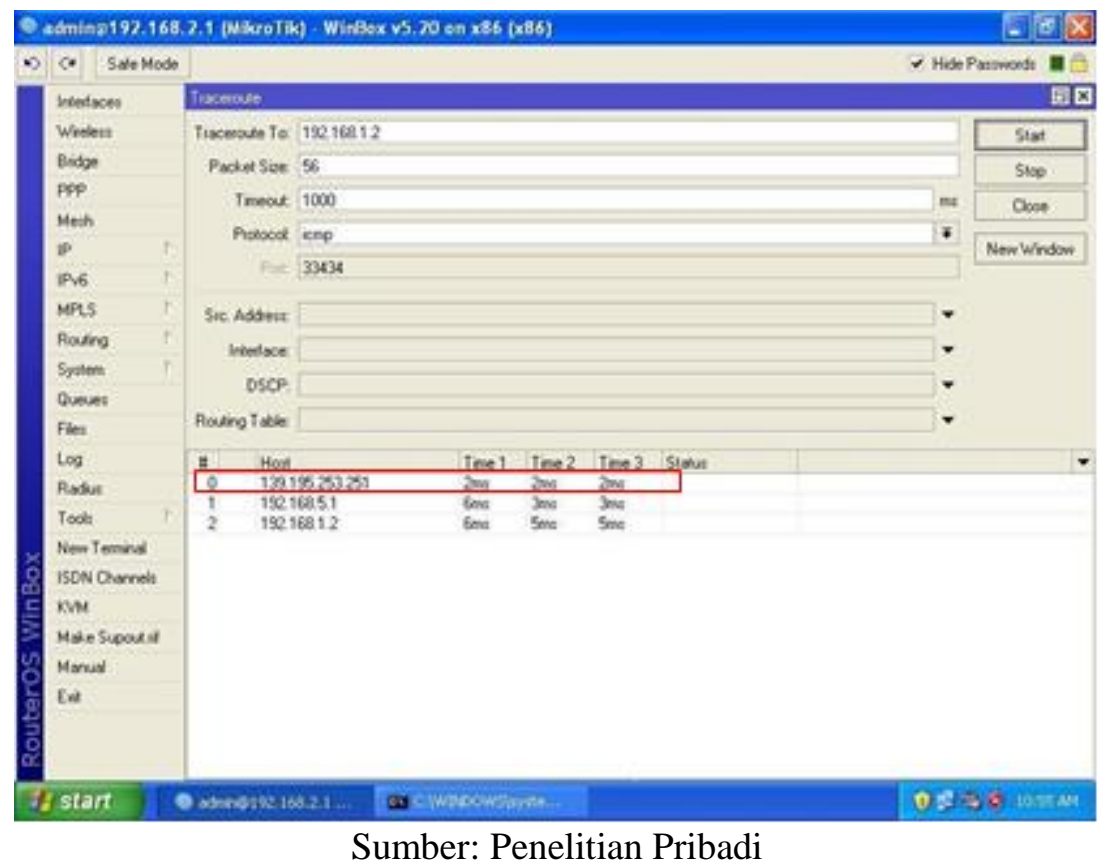

Gambar 12. Traceroute setelah pemutusan koneksi internet pada interface "ether1-firstmedial"

Dari gambar 11, bahwa setelah pemutusan line koneksi interface "etherl-firstmedial" gateway berpindah ke interface "ether2- firstmedia2", hal itu dibuktikan dengan adanya lalu lintas data pada interface tersebut. Sedangkan gambar 12, IP gateway 
sebelumnya juga sudah berubah dari IP 139.228.189.227 menjadi IP 139.195.253.251 setelah terjadi pemutusan line koneksi. Dengan demikian koneksi internet sudah berpindah ke ISP yang satu ke ISP yang lain masih aktif koneksi internetnya. Tahap berikutnya melakukan pemutusan koneksi internet yaitu interface "ether2-firtsmedia2" dengan cara mendisable interface.
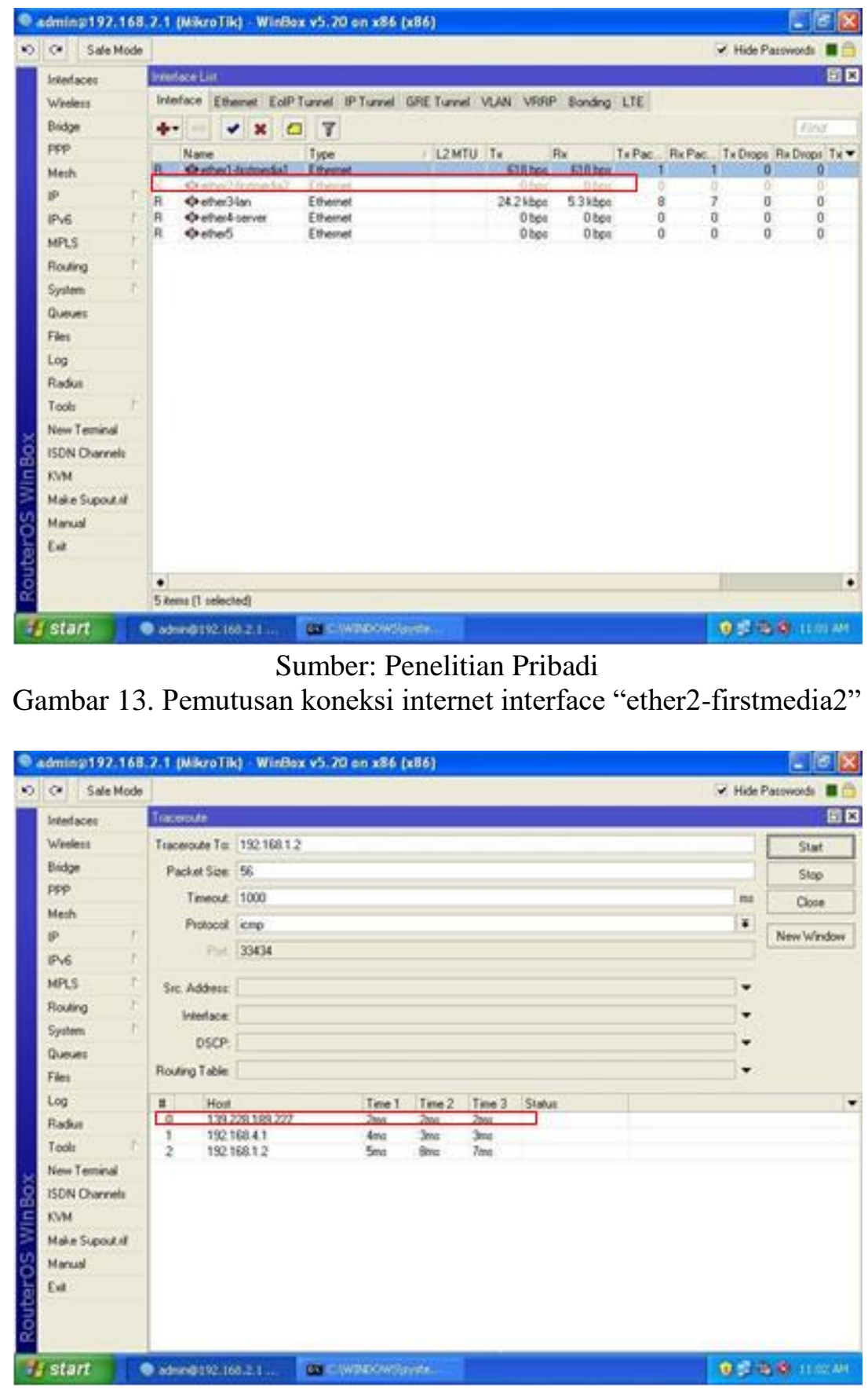

Sumber: Penelitian Pribadi

Gambar 14. Hasil traceroute setelah pemutusan koneksi internet interface "ether2-firstmedia2"

Dari gambar 13, setelah pemutusan koneksi internet interface "ether2firstmedia2", secara otomasti gateway berpindah ke interface "ether2-firstmedia2". Sedangkan gambar 14, IP gateway juga sudah berubah menjadi 139.228.189.227.
Berdasarkan hasil pengujian failover tersebut, dapat dianalisa bahwa konfigurasi sistem failover sudah berjalan dengan baik. Hal itu dibuktikan dengan pada saat pemutusan salah satu line koneksi internet, sistem secara otomatis akan berpindah pada 
ISP yang masih aktif. Hal tersebut juga berlaku ketika salah satu line koneksi internet terputus maka ISP yang aktif akan otomatis membackup koneksi internet seluruh jaringan.

\section{KESIMPULAN}

Berdasarkan implementasi Load Balancing dan FailOver pada aplikasi GNS3, dengan adanya implementasi load Balancing terjadi peningkatan bandwidth koneksi internet, tetapi load balancing tidak menyatukan dua bandwidth ISP tersebut karena teknik load balancing bukan berarti $512+256=768$ melainkan $512+256=512+$ 256. Implementasi load balancing menggunakan metode PCC pada aplikasi GNS3 berhasil menyebarkan jumlah beban koneksi pada semua gateway ISP yang digunakan secara seimbang. Tetapi besar paket yang dilewatkan pada masing-masing ISP tidak seimbang, hal ini dikarenakan metode PCC hanya membagi berdasarkan koneksi bukan dari besar paket yang lewat ISP tersebut. Penerapan teknik Fail Over sudah berfungsi dengan baik. Ketika salah satu gateway terputus atau mengalami gangguan koneksinya maka semua beban koneksi internet akan dialihkan secara otomatis ke gateway lainnya yang masih aktif.

\section{REFERENSI}

Abdullah, M. T., Qidri, S., Nuryadi, W., \& Widianto, S. R. (2020). Failover Cluster Nodes and ISCSI Storage Area Network on Virtualization Windows Server 2016. JOIN (Jurnal Online Informatika), 5(1), 89-96. https://doi.org/10.15575/join.

Adhiwibowo, W., \& Irawan, A. R. (2019). Implementasi Redundant Link Untuk Mengatasi Downtime Dengan Metode Failover. Jurnal Pengembangan Rekayasa Dan Teknologi, 15(1), 48. https://doi.org/10.26623/jprt.v15i1.1490

Christanto, F. W., Susanto, S., \& Priyanto, A. (2019). Load Balancing-Failover Methods using Static Route with Address List, ECMP, PCC, and Nth for Optimizing LAN Network: A Comparison. International Journal of Communication Networks and Information Security, 11(3), 409-416.

Cristescu, G. C., Croitoru, V., \& Sorici, V. (2016). Implementing an AAARADIUS solution based on legacy authentication protocols. 2016 12th

International Symposium on Electronics and Telecommunications, ISETC 2016 Conference Proceedings, 75-80. https://doi.org/10.1109/ISETC.2016.778 1061

Discher, S. (2016). Load Balancing Using. What Is Load Balancing and Why Would I Want It?, 29-33. Retrieved from https://mum.mikrotik.com/presentations/ US12/steve.pdf

Djumhadi, D., \& Roring, R. S. (2020). Perancangan Dan Implementasi Jaringan Failover Menggunakan Protokol Spanning Tree Pada Pt. Pln Up3B Kalimantan Timur. Jurnal Ilmiah Matrik, 22(3), 249-256. https://doi.org/10.33557/jurnalmatrik.v2 $2 \mathrm{i} 3.1120$

Duque, J. P., Beltrán, D. D., \& Leguizamón, G. P. (2018). OpenDaylight vs. floodlight: Comparative analysis of a load balancing algorithm for software defined networking. International Journal of Communication Networks and Information Security, 10(2), 348357.

Johnson, R. A., Wild, K., \& Quammen, G. (2012). (12) United States Patent. 2(12). Retrieved from https://patentimages.storage.googleapis. com/6a/9c/f1/c2fc5cc1425463/US83417 22.pdf

Jose, S. (2006). Cisco Unified Communications System for Contact Center Release 5 . 1 ( 1 ). Communications, 1(1).

Mishra Assistant Professor, A. (2015). Network Load Balancing and Its Performance Measures. International Journal of Computer Science Trends and Technology, 3(1), 77-81. Retrieved from www.ijcstjournal.org

Pauzhi, W., \& Coronel, J. (2015). Security for WISP through Mikrotik equipment Mikrotik ). 2015 CHILEAN Conference on Electrical, Electronics Engineering, Information and Communication Technologies (CHILECON), 229-233. Santiago, Chile.

Rahman, T. (2017). Implementasi Jaringan Vpn Eoip Tunnel Menggunakan Gns3. 306-314.

Safrianti, E. (2021). Peer Connection 
Classifier Method for Load Balancing Technique. International Journal of Electrical, Energy and Power System Engineering, 4(1), 127-133. https://doi.org/10.31258/ijeepse.4.1.127133

Setiawan, R., Kartikasari, D. P., Rahayudi, B., Ilmu, F., Universitas, K., \&

Korespondensi, P. (2021). Implementasi Arsitektur Web Server Cluster Menggunakan Single Board Computer
Untuk Menunjang Kebutuhan High Implementation of Web Server Cluster Using Single Board. Nasional, 8(2), 329-332. https://doi.org/10.25126/jtiik.202184512 Yuan, C., Du, J., Yue, M., \& Ma, T. (2020). The design of large scale IP address and port scanning tool. Sensors (Switzerland), 20(16), 1-12. https://doi.org/10.3390/s20164423 